\title{
Factors Influencing Preventive Behaviors of Mothers for Diarrhea in Children Aged 1-5 Years in Buol District, Indonesia
}

\author{
Helmi Rumbo ${ }^{a}$, Susheewa Wichaikullb, Boosaba Sanguanprasit ${ }^{b}$
}

\begin{abstract}
This study aims to determine the factors related with mothers' behaviors in preventing diarrhea in children aged 1-5 years in Buol District. This was a cross-sectional survey design with health belief model as the conceptual framework. A total of 300 mothers were selected by using purposive sampling method based on criteria. Mothers were interviewed by using a structured questionnaire during October to November 2015. A chi-square $\left(\chi^{2}\right)$ test was used to determine a significant association between independent variables and dependent variable. The finding showed that $68.3 \%$ of mothers had good behaviors in preventing diarrhea. The factors significantly related to mothers' behaviors included perceived susceptibility to diarrhea, perceived severity of diarrhea, perceived benefits of diarrhea prevention behaviors, and perceived barriers of diarrhea prevention behaviors $(p<.01, p<.01, p<.01$, and $p<.01$ respectively). Further, mothers had high perception to comply with diarrhea prevention behaviors. Those who perceived that diarrhea prevention behaviors were highly beneficial to their children had good behaviors in preventing diarrhea. However, taking certain actions must consider negative aspects.
\end{abstract}

\section{Keywords}

Mothers' perceptions and behaviors, preventing diarrhea, children aged 1-5 years

According to the world statistics of 2012, the estimation of incidence rates of diarrhea was 9,290 cases $/ 100,000$ children. In Southeast Asia region, it was 9,680 cases/100,000 children (WHO 2012). In Indonesia, the statistics of 2013 showed that the incidence case of diarrhea among children under five years was $6.7 \%$. The number was higher than the incidence case of diarrhea of all age groups combined. Diarrhea kills more young children compared to malaria and measles combined. Diarrhea in children under five years was more prevalent in developing country (WHO 2014). Diarrhea is defined as the liquid feces and/or passing more than three times of loose feces per day. The major causes of acute diarrhea were commonly identified as bacteria, viruses, and parasitic worms (WHO 2013). Child with diarrhea accompanies many childhood disorders and is associated with rapid weight loss (Mandell, Bennetts, and Dolin 2010). Diarrhea may manifest insidiously. The signs and symptoms include dry/hot skin, changes in skin turgor and texture. Feces appearance seems

aKasetsart University, Thailand

bBoromarajonani College of Nursing Nopparat Vajira, Thailand

\section{Correspondent Author:}

Helmi Rumbo, Jl. Towua 114, Birobuli Selatan, Palu, Central Sulawesi, Indonesia (94113) 
large in volume, light or dark in color, and loose to watery in texture. The vital signs included heart rate increase, respiratory rate increase, and high temperature. Finally, children with diarrhea must be assessed for the presence of dehydration because decreased fluid intake or increased fluid loss may cause dehydration; both body fluids and electrolyte deficiency (McKinney et al. 2013). Severe dehydration can cause seizures, brain damage, and death (Shah 2009).

Factors relating to diarrhea in children are behavioral and environmental. Behavioral factors mean unhygienic behaviors of the children and/or of the mothers or any person caring for the children in daily routines. Environmental factors included poor sanitation, poor domestic hygiene, and unavailable access to clean water (WHO 2013).

The principle of public health is being the first in primary prevention. The goal of primary prevention is to avoid interference before the problem starts (without signs and symptoms of illness). These actions will be successful if people consider about the etiology and severity of the disease (McKinney et al. 2013). An approach to preventing diarrhea in children is focused on hygiene improvement, which could block the transmission/pathway of diarrhea disease. The F-diagram was a comprehensive hygiene improvement consisting of improved sanitation, washing hands, increased water quantity, and improved water quality. These prevention interventions can be applied at the level of individual, family, and community (EHP 2004).

As the primary caregiver to their children, mothers' perceptions towards diarrhea and their behaviors are the factors relating to diarrhea in children. A mother plays an important role in family as a health leader during the golden time of growth and development of children. Mothers' role in primary disease prevention is an important factor (Friedman, Bowden, and Jones 2003). Further, mothers' behaviors in preventing diarrhea in children included safe drinking water, proper disposal of feces, appropriate hand washing, and safe food preparations/feeding practice.

According to previous studies, theory of health behaviors has been used to explain the way of person to take their health behavior. Health belief model is applicable to identify the factors influencing people who can take preventive actions (avoid disease, avoid complication, and avoid disability). Health belief model might explain that people would take action for two reasons: a perceived threat to health and the conviction that the benefit of taking protection/preventive action was greater than the barriers that would be faced (Pender, Murdaugh, and Parsons 2011). This model had been applied in several studies previously conducted on diarrhea prevention behaviors of caregivers with children under five years (Ha 2009; Kundu, Prateepchaikul, and Ngam 2010; Htay, Keiwkarnka, and Hongkailert 2010; Aye 2014; Morgan 2014). This study uses health belief model as the conceptual framework to explore mothers' perceptions towards diarrhea and mothers' behaviors in preventing diarrhea in children aged 1-5 years in Buol District, Central Sulawesi, Indonesia.

Buol is one of 11 districts in Central Sulawesi, Indonesia. Based on a survey in 2012, out of 27,987 households, $47.2 \%$ households had proper dumps for their trash disposal, $31.8 \%$ had good means to handle their wastewater, $65.1 \%$ had safe drinking water, and $45.5 \%$ had latrine. The findings indicated that Buol people had a poor behavior in performing hygienic and healthy life style in Central Sulawesi Province. These situations might put the children at high risk of having diarrhea because of poor environmental sanitation and poor personal hygiene. Therefore, a research study was conducted to determine factors related with mothers' behaviors in preventing diarrhea in children aged 1-5 years in Buol District. The finding of this study is useful to give information for health care providers and provides a reference for future interventions. 


\section{METHODS}

\section{Study Design}

This research study was a cross-sectional survey design. The population of this study was mothers with children aged 1-5 years living in Buol District. The sample size in the study was 178 samples. The sample size was multiplied by 1.5 as design effect. To anticipate the incomplete information, the number of samples has been increased $10 \%$. Finally, the sample size for this study was 300 mothers.

\section{Sampling Technique}

This study uses multistage sampling technique. There were 11 subdistricts included 115 villages in Buol District with total of 13,975 children aged 1-5 years (Statistics Indonesia 2010). Simple random sampling was used to select six subdistricts and the villages. The number of sample of each village was estimated by using proportional to size, because every village had different area and population density. A total of 300 houses were visited and there was no mother dropped out. The number of participating mothers for each village was 31, 85, 31, 63, 53, and 37 (Bukaan, Kel. Buol, Bunobogu, Paleleh, Air Terang, and Mooyong respectively).

\section{Ethical Consideration}

This study was approved by The Ethical Review Board of Boromarajonani College of Nursing Nopparat Vajira on October 6, 2015 (ERB No. 22/2558).

The researchers provide an information sheet and give an opportunity to the mothers for asking any question about this study. Mothers who agreed with the requirements signed the informed consent in front of the researchers. In addition, withdrawal from this study was permitted in any time and the mothers had rights to not answer any question.

\section{Measurement}

The questionnaire of mothers' behaviors in diarrhea prevention consisted of four parts including general characteristics, knowledge of diarrhea, perceptions toward diarrhea in children, and mothers' behaviors in diarrhea prevention. General characteristics consist of demographics data of the mother-child dyad such as mothers' age, marital status, occupation, child's age, and episode of diarrhea in the last month.

The independent variables were composed of age, knowledge about diarrhea, and mothers' perception toward diarrhea in children. Mothers were asked about their knowledge in identifying diarrhea in children, and this part provided three responses (yes, no, and don't know). The score was given for each item (1 and 0 respectively). It was categorized into three groups: poor ( $0 \%-59 \%)$, moderate (60\%-79\%), and good (80\%-100\%). In this study, the KR-20 was .708.

Perceived susceptibility to diarrhea and perceived severity of diarrhea provided five responses. The score was given for each item according to the answer such as highly likely, likely, not sure, unlikely, and highly unlikely $(4,3,2,1$, and 0 respectively). The total score had been categorized into three groups: low, moderate, and high. The Cronbach's Alpha of perceived susceptibility to diarrhea was .951 ; perceived severity of diarrhea was .856 .

Perceived benefits of diarrhea prevention behaviors provided five responses, and the score was given for each item according to the answer such as strongly agree, agree, uncertain, disagree, and strongly disagree $(4,3,2,1$, and 0 respectively). The total score had been categorized into three groups: low, moderate, and high. The Cronbach's Alpha was .897.

Perceived barriers to diarrhea prevention behaviors provided three responses (yes, no, and why). The score was given for each item according to the answer ( 0 and 1 respectively). The total score had been categorized into three groups: low, moderate, and high. The Cronbach's Alpha was .808 .

Mothers were assessed for their behaviors in daily routines for preventing diarrhea in children, which included providing safe drinking water, disposing the 
feces properly, washing hands, and safe food preparation. This part provided three responses (always, not always, and never). The score was given for each item according to the option (3, 2, and 1 respectively). The total score had been categorized into three groups (low, moderate, and high). The Cronbach's Alpha was .863.

\section{RESULTS}

General characteristics of the participants were described in Table 1. Data revealed that mothers' age ranged from 18 to 48 years, with the mean of age 29.9 years $(\mathrm{SD}=7.3)$. Almost three-fourths of mothers were aged 20 to 35 years and $65.7 \%$ of mothers completed the nine-year compulsory education. From 300 mothers enrolled in this study, $97.3 \%$ of mothers were married and $83.7 \%$ of mothers were unemployed being the housewives (see Table 1).

Mothers' knowledge about diarrhea in children, perceived susceptibility to diarrhea, perceived severity of diarrhea, perceived benefits of diarrhea prevention behaviors, and perceived barriers of diarrhea prevention behaviors are presented in Table 2 .

The total mean score of mothers' knowledge about diarrhea, perceived susceptibility to diarrhea, perceived severity of diarrhea, perceived benefits of diarrhea prevention behaviors, and perceived barriers of diarrhea prevention behaviors were $12.6(\mathrm{SD}=2.8)$, $21.9(\mathrm{SD}=4.2), 19.2(\mathrm{SD}=4.2), 25.8(\mathrm{SD}=3.6)$, and $1.6(\mathrm{SD}=1.3)$ respectively (see Table 2$)$.

The relationships among mothers' age, knowledge, and perceptions variables by diarrhea prevention behaviors are presented in Table 3.

By using chi-square test, the results show no statistically significant relationship between mothers' age and mothers' behaviors in preventing diarrhea in children aged 1-5 years. This indicated that age differences between mothers were not associated with being better in performance or being good in behaviors to prevent diarrhea. The result showed no statistically significant relationship between mothers' knowledge and mothers' behaviors in preventing diarrhea in children aged 1-5 years. This indicated that good knowledge was not associated with better performance or good behaviors to prevent diarrhea.

The results revealed a significant relationship between mothers' perceived susceptibility to diarrhea and mothers' behaviors in preventing diarrhea in children aged 1-5 years. Those who perceived that their children were highly susceptible to diarrhea had good behaviors in preventing diarrhea than those who perceived that their children were lowly or fairly susceptible to diarrhea. It was a positive relationship and the strength was moderate ( $\mathrm{phi}=.3$ ).

There was a significant relationship between mothers' perceived severity of diarrhea and mothers' behaviors in preventing diarrhea in children aged 1-5 years. Those who had lowly or fairly perceived severity of diarrhea had good behaviors in preventing diarrhea than those who had highly perceived severity of diarrhea. It was negative relationship and the strength was low (phi=-.1).

There was a significant relationship between mothers' perceived benefits of diarrhea prevention behaviors and mothers' behaviors in preventing diarrhea in children aged 1-5 years. Those who perceived that diarrhea prevention behaviors were highly beneficial to their children had good behaviors in preventing diarrhea than those who perceived that diarrhea prevention behaviors were lowly or fairly beneficial to their children. This relationship was positive and the strength was moderate $(\mathrm{phi}=.3)$.

There was a significant relationship between mothers' perceived barriers to diarrhea prevention behaviors and mothers' behaviors in preventing diarrhea in children aged 1-5 years. Those who perceived no barriers to diarrhea prevention behaviors had good behaviors in preventing diarrhea than those who had perceived barriers to diarrhea prevention. This relationship was negative and the strength was moderate $(\mathrm{phi}=-.3)$. 
Table 1. Number and Percentage of General Characteristics of Mothers $(n=300)$

\begin{tabular}{lll}
\hline & Frequency & Percentage (\%) \\
\hline Age & & \\
\hline$<20$ years & 11 & 3.6 \\
$20-35$ years & 221 & 73.7 \\
$\geq 36$ years & 68 & 22.7 \\
Mean \pm SD $=29.9 \pm 7.3$ years & & \\
Min-Max = 18-48 years & & \\
Level of education & 103 & 34.3 \\
\hline Lower than junior high school & 197 & 65.7 \\
Junior high school and above & & \\
\hline Occupation & 251 & 83.7 \\
Housewife & 29 & 9.7 \\
Employee & 9 & 3.0 \\
Farmer & 11 & 3.7 \\
Entrepreneur & &
\end{tabular}

Note: Source: H. Rumbo (2016).

Table 2. Levels of Knowledge About Diarrhea, Perceptions of Mothers Toward Diarrhea, and Mothers' Behaviors in Preventing Diarrhea

\begin{tabular}{llllll}
\hline Variables & Poor & Moderate & High & Total & Mean \pm SD \\
\hline Knowledge about diarrhea & $46(15.3 \%)$ & $71(23.7 \%)$ & $183(61.0 \%)$ & $300(100 \%)$ & $12.6 \pm 2.8$ \\
Perceived susceptibility & $24(8.0 \%)$ & $171(57.0 \%)$ & $105(35.0 \%)$ & $300(100 \%)$ & $21.9 \pm 4.2$ \\
Perceived severity & $41(13.7 \%)$ & $107(35.7 \%)$ & $152(50.7 \%)$ & $300(100 \%)$ & $19.2 \pm 4.2$ \\
$\begin{array}{l}\text { Perceived benefits of diarrhea } \\
\text { Perceived barriers to diarrhea }\end{array}$ & $300(2.0 \%)$ & $191(63.7 \%)$ & $103(34.3 \%)$ & $300(100 \%)$ & $25.8 \pm 3.6$ \\
$\begin{array}{l}\text { Mothers' behaviors in } \\
\text { preventing diarrhea }\end{array}$ & $3(1.0 \%)$ & - & - & $300(100 \%)$ & $1.6 \pm 1.3$ \\
\hline
\end{tabular}

Note: Source: H. Rumbo (2016).

Table 3. The Distribution of Mothers' Age, Knowledge, and Perceptions Variables by Diarrhea Prevention Behaviors $(\mathrm{n}=300)$

\begin{tabular}{|c|c|c|c|c|c|c|}
\hline & \multicolumn{2}{|c|}{ Mother's behaviors } & \multirow{2}{*}{ - Tot. } & \multirow{2}{*}{$\chi^{2}$} & \multirow{2}{*}{$\mathrm{P}$} & \multirow{2}{*}{ Phi } \\
\hline & Fair & Good & & & & \\
\hline Mothers' age & - & - & - & .7 & .401 & .049 \\
\hline$<20$ and $>35$ years & $28(35.4 \%)$ & $51(64.4 \%)$ & 79 & & & \\
\hline 20-35 years & $67(30.3 \%)$ & $154(69.7 \%)$ & 221 & & & \\
\hline Knowledge of diarrhea & - & - & - & .0 & .789 & -.0 \\
\hline Needs improvement & $36(30.8 \%)$ & $81(69.2 \%)$ & 117 & & & \\
\hline Good & $59(32.2 \%)$ & $124(67.8 \%)$ & 183 & & & \\
\hline Perceived susceptibility to diarrhea & - & - & - & 25.0 & .000 & .3 \\
\hline Low-Fair & $81(41.5 \%)$ & $144(58.5 \%)$ & 195 & & & \\
\hline High & $14(13.3 \%)$ & $91(86.7 \%)$ & 105 & & & \\
\hline Perceived severity of diarrhea & - & - & - & 7.2 & .007 & -.1 \\
\hline Low-Fair & $36(24.3 \%)$ & $112(75.7 \%)$ & 148 & & & \\
\hline
\end{tabular}


Table 3 continued

\begin{tabular}{|c|c|c|c|c|c|c|}
\hline & \multicolumn{2}{|c|}{ Mother's behaviors } & \multirow{2}{*}{ - Tot. } & \multirow{2}{*}{$\chi^{2}$} & \multirow{2}{*}{$\mathrm{P}$} & \multirow{2}{*}{ Phi } \\
\hline & Fair & Good & & & & \\
\hline High & $59(38.8 \%)$ & $93(61.2 \%)$ & 152 & & & \\
\hline Perceived benefits of diarrhea & - & - & - & 26.2 & .000 & .3 \\
\hline Low-Fair & $82(41.6 \%)$ & $115(58.4 \%)$ & 197 & & & \\
\hline High & $13(12.6 \%)$ & $90(87.4 \%)$ & 103 & & & \\
\hline Perceived barriers to diarrhea & - & - & - & 36.5 & .000 & -.3 \\
\hline No barrier & $2(2.8 \%)$ & $70(97.2 \%)$ & 72 & & & \\
\hline 1 and more barriers & $93(40.8 \%)$ & $135(59.2 \%)$ & 228 & & & \\
\hline
\end{tabular}

Note: Source: H. Rumbo (2016).

\section{DISCUSSION}

It has been found that over than two thirds (68.3\%) of mothers had good behaviors in preventing diarrhea in children aged 1-5 years in Buol District. This includes safe drinking water, proper disposal of feces, personal hygiene, and safe food preparations and feeding practices. According to the results of a survey in 2012, less than one fourth (24.2\%) of Buol people had good behaviors in practicing hygienic and healthy life style. There were 10 practices that were assessed in the survey. Out of the 10 behaviors, two behaviors were used as the reference for this study. These findings indicate that within three years, two of the health behaviors have been improved.

It has been found that age did not have significant relationship with mothers' behaviors in preventing diarrhea in children in this study. This finding is supported by the previous studies explaining that age was not related to health behaviors; the older caregiver would be more unlikely to perform good behaviors in preventing diarrhea in children (Chowdhury 2010; Htay et al. 2010). According to this study, age did not directly determine mothers' behaviors. Because there were several interconnected factors that influenced the process of human development, including experiences, knowledge, education, and personality trait (Barkley 2008).

It has been presented that mothers' knowledge had no significant relationship with mothers' behaviors in preventing diarrhea in children. It can be inferred that good knowledge was not associated with better performance or good behaviors in preventing diarrhea. This is consistent with the previous studies explaining that knowledge had not influenced behaviors (Liu 2009; Morgan 2014).

It has been found that mothers' perceived susceptibility to diarrhea had positively significant relationship with mothers' behaviors in preventing diarrhea in children. It can be interpreted that mothers perceived that if they did not comply with proper prevention behavior, their children would be more likely to get diarrhea. This is consistent with another study found that perceived susceptibility to diarrhea is influential to diarrhea prevention behaviors (Kundu et al. 2010). This finding was supported by health belief model, which described that those who had highly perceived susceptibility to disease would be more likely to take any action to avoid the disease (Becker 1974).

According to the result, it presents that mothers' perceived severity of diarrhea had negatively significant relationship with mothers' behaviors in preventing diarrhea in children. This is supported by previous studies, which found that those who had perceived severity of diarrhea would be more unlikely to do good behaviors in preventing diarrhea (Ha 2009). Perceived severity refers to individual convictions concerning the seriousness of the disease. If people 
are ready, they would take any action to reduce the severity of the disease. However, taking certain actions must consider negative aspects or situations. When the readiness to act was high and the negative aspects were relatively weak, the positive action would be taken, or vice versa (Becker 1974).

It has been found that mothers' perceived benefits of diarrhea prevention behaviors had positively significant relationship with mothers' behaviors in preventing diarrhea in children. This is consistent with the other findings, which explained that those who perceived that diarrhea prevention behaviors have benefits to their children would practice it properly (Ha 2009). This finding was supported by health belief model, which described that those who perceived that the actions were beneficial to reduce the threat of disease would like to take the actions to avoid the disease (Becker 1974).

The result presents that mothers' perceived barriers to diarrhea prevention had negatively significant relationship with mothers' behaviors in preventing diarrhea in children. It can be inferred that mothers who perceived no barriers to diarrhea prevention behaviors had good behaviors in preventing diarrhea than mothers who had perceived barriers to diarrhea prevention. This is supported by previous study, which explained that those who had perceived barriers to diarrhea prevention behaviors were more unlikely to perform diarrhea prevention behaviors (Morgan 2014). According to health belief model, barriers (the negative aspects) could disrupt the line to take good actions (Becker 1974). The data revealed that some of mothers had some barriers to practice good behaviors in preventing diarrhea including shortage of water supply, unavailability of toilet and residential situation in their living area.

\section{LIMITATION OF THE STUDY}

The limitations of this study do not include observation data and all multifactor that influence mothers' behaviors in diarrhea prevention in children aged 1-5 years, such as infrastructures of villages (water supply in the village, drainage of water to each house, garbage management), culture and the institutional factors. This study also used purposive sampling method to collect the data (with inclusion criteria). This method might not be representative for the population.

\section{CONCLUSIONS}

This was a cross-sectional survey design. Health belief model was used as the conceptual framework. The purpose of this study was to determine factors that predicted the behaviors of mothers in preventing diarrhea among children from the ages 1-5 in Buol District, Central Sulawesi, Indonesia. The total sample was 300 mothers, and this included 210 from seasides and 90 from inland/rural. This study was conducted during October to November 2015.

The results revealed that mothers' behaviors in preventing diarrhea in children aged 1-5 years had statistically significant relationship with mothers' perceived susceptibility to diarrhea, perceived benefits of diarrhea prevention behaviors. However, the results found negatively significant relationship with perceived severity of diarrhea and perceived barriers to diarrhea prevention behaviors.

\section{Recommendations}

To community nursing/health care providers, the findings are usable for supportive information to design an intervention in relation with mothers and children health; also to reduce the incidence of diarrhea in children as an infectious disease.

\section{Acknowledgements}

The highest appreciation for the thesis advisors: Dr. Susheewa Wichaikull and Asst. Prof. Boosaba Sanguanprasit. Big thanks to participants who have been willing as the volunteers in this project. Very special thanks to parents, siblings, and friends. 


\section{Funding}

This research study was supported by personal fund.

\section{References}

Aye, K. K. 2014. "Food Hygiene and Food Safety Behaviors of Mothers on Diarrhea in 6-59 month-old children in Taze Township, Sagaing Region, Myanmar." M.Sc. thesis, Mahidol University.

Barkley, G. S. 2008. "Factors Influencing Health Behaviors in the National Health and Nutritional Examination Survey, III (NHANES III)." Social Work in Health Care 46(4):57-79.

Becker, M. H. 1974. The Health Belief Model and Personal Health Behavior. San Francisco: Society for Public Health Education.

Centers for Disease Control and Prevention (CDC). 2014. Disease \& SWS Impact. Retrieved January 11, 2015 (http://www.cdc.gov/safewater/disease.html).

- 2015. When \& How to Wash Your Hands. Retrieved (http://www.cdc.gov/handwashing/when-how-handwashing .html).

Child Health Epidemiology Reference Group (CHERG). 2014. Underlying Causes of Child Death. Retrieved (http://cherg. org/projects/underlying_causes.html).

Chowdhury, F. 2010. "Diarrhea Preventive Practice Among Caregivers of 1 to 5 Years Children at Urban Slum Area in Chittagong, Bangladesh." M.Sc. thesis, Mahidol University.

Environmental Health Project (EHP). 2004. The Hygiene Improvement Framework: A Comprehensive Approach for Preventing Childhood Diarrhea. Retrieved (http://www.ehproject.org/PDF/Joint_Publications/JP008-H IF.pdf).

Friedman, M. R., V. R. Bowden, and E. Jones. 2003. Family Nursing Research Theory and Practice. 5th ed. Upper Saddle River, New Jersey: Pearson Education, Inc.

Ha, N. T. L. 2009. "Diarrhea Preventive Behavior of Mothers With Children at Age Between 2 and 5 Years Old at Sao Mai School, Cau Giay District, Hanoi City, Vietnam.” M.Sc. thesis, Mahidol University.

Htay, W. Y. A., B. Keiwkarnka, and N. Hongkailert. 2010. Diarrhea Preventive Behavior of Myanmar Immigrant Caregivers With Children Under Five Years in Muang District, Samut Sakhon Province, Thailand. Retrieved (http://www.aihd.mahidol.ac.th/sites/default/files/images/ne w/pdf/journal/janapr2011/1.pdf).

Kundu, T. R., L. Prateepchaikul, and K. S. Ngam. 2010. Relationship Between Maternal Perceptions and Preventive Behaviors Regarding Acute Diarrhea of Children in
Bangladesh. Retrieved (http://tar.thailis.or.th/bitstream/123 456789/929/1/009.pdf).

Liu, J. 2009. Maternal Beliefs and Behaviors in the Prevention of Childhood Diarrhea in Dar es Salaam, Tanzania. Retrieved (https://studentaffairs.stanford.edu/sites/default/ files/haas/files/Jessie\%20Liu\%20Thesis.pdf).

Mandell, G. L., J. E. Bennetts, and R. Dolin. 2010. Principle and Practice of Infectious Disease. Philadelphia: Churchill Livingstone, Elsevier.

McKinney, E. S., S. S. Murray, J. Ashwill, S. R. James, and K. Nelson. 2013. Maternal-Child Nursing. 4th ed. Missouri: Saunders, Elsevier Inc.

Ministry of Health Republic of Indonesia. 2008. Five Ways Against Diarrhea. Director General of Disease Control and Environmental Sanitation. Retrieved (http://www.basics.org/documents/Lintas_Diare_Pocket_B ook.pdf).

—. 2012. Health Profile of Central Sulawesi. Retrieved (http://www.depkes.go.id/resources/download/profil/PROFIL KES_PROVINSI_2012/25_Profil_Kes.Prov.SulawesiTenga h_2012.pdf).

_ 2014. Indonesia Health Profile. Retrieved (http://www. depkes.go.id/folder/view/01/structure-publikasi-pusdatin-pr ofil-kesehatan.html).

Morgan, M. S. 2014. "Diarrhea Preventive Behavior Among the Caregivers of Children Under Five Years Old in the Tonle Sap Great Lake Floodplains, Siem Reap, Cambodia." M.Sc. thesis, Mahidol University.

Nelson, W. 1998. Textbook of Pediatrics. 15th ed. Harkcourt Brace and Company, Asia PTE LTD 583 Orchard 09-01, Singapore.

Pender, N. J., C. L. Murdaugh, and M. A. Parsons. 2011. Health Promotion in Nursing Practice. 6th ed. Upper Saddle River, New Jersey: Pearson Education, Inc.

Polit, D. F. and C. T. Beck. 2012. Nursing Research: Generating and Assessing Evidence for Nursing Practice. International Edition 9th ed. Philadelphia: Lippincott Williams \& Wilkins.

Statistics Indonesia. 2010. Population of Buol District. Retrieved (http://sp2010.bps.go.id/index.php/site?id=72000 00000\&wilayah=Sulawesi-Tengah).

Shah, S. S. 2009. Pediatric Practice Infectious Disease. New York, NY: McGraw-Hill.

World Health Organization (WHO). 2012. Health Statistics and Information Systems, Estimates 2000-2015 Disease Burden. Retrieved (http://www.who.int/healthinfo/global_burden disease/estimates/en/index2.html).

- 2013. Diarrhoeal Disease. Retrieved (http://www.who. int/mediacentre/ factsheets/fs330/en/).

_ 2014. Indonesia: WHO Statistical Profile. Retrieved (http://www.who.int/gho/countries/idn.pdf?ua=1). 


\section{Bios}

Helmi Rumbo, S.Kep., Ns., MNS, Kasetsart University, Bangkok, Thailand; research field: family and community health nursing.

Susheewa Wichaikull, Ph.D., RN, Boromarajonani College of
Nursing Nopparat Vajira, Khannayao, Bangkok, Thailand; research field: family and community health nursing.

Boosaba Sanguanprasit, MPH, Ph.D., assistant professor, Boromarajonani College of Nursing Nopparat Vajira, Khannayao, Bangkok, Thailand; research field: family and community health nursing. 